\title{
Elastic resistance training: resistance exercise alternative in the home envi- ronment during Covid-19 pandemic
}

Marcus Vinícius de Almeida Campos'

Henrique Miguel $^{2}$

Among the measures adopted to contain the pandemic of COVID-19, is the closing of gyms and the limitation of the use of common spaces for physical exercise, consequently interrupting the training not only of athletes but also of non-athletes practicing resistance training.

This interruption leads practitioners to undergo a readjustment of the entire body biological system, in response to the reduction of physical stimuli promoted by training. This fact encourages the occurrence of an important principle of sports training, the principle of reversibility, which triggers the reversal morphological and functional adaptations obtained with physical training, a process known as detraining [1].

So aiming to avoid or at least reduce or target, quarantine limits are used interchangeably for exercises used in their homes, using a series of methods proposed in the literature or even by bloggers.

However, such methods do not pay attention to an important principle of resistance training, the principle of continuity, where Miguel et al. [2] warn that not only the interruption of the training program leads to detraining, but also the realization of it without due attention to the training variables. It is necessary to use alternative methods capable of controlling such variables in the most individualized way possible, but with an affordable cost and good adaptability to the available physical space.
In this scenario, the use of elastic resistance training can be an excellent alternative, since elastic resistance devices have low cost in the acquisition and use of implements, easy applicability for different groups of people, need for small physical spaces, easy adaptation for the individuality and specificity of the practitioner and good variability of exercises [3-6].

\section{Elastic Resistance Training}

There are two different ways of carrying out this methodology, which highlight specific factors of the individual training component: the hybrid elastic resistance, in which the elastic resistance (bands or tubes) is used together with traditional weights, this method is often used in the sports area, aiming better development of power, acceleration and movement speed in athletes. And the simple elastic resistance, where only elastic bands and elastic tubes are used, the resistance being given by the intensity of the band or tube [7].

The manufacturers of elastic bands and tubes provide a line of products with different levels of resistance that are normally distinguished by colors, which makes it possible to use the elastic band that best corresponds to the degree of resistance for successful training.

This possibility of determining the training load allows the elastic resistance training to be effective for both men and women, being observed by Hostler et al. [8]

\footnotetext{
${ }^{1}$ Physical Education Department, Faculdade Euclides da Cunha College - FEUC. Rua Jorge Tibiriçá, 451, Centro, São José do Rio Pardo, SP, Brasil.Correspondence to: MVA CAMPOS. Email: <mvacampos@yahoo.com.br>.

${ }^{2}$ Physical Education Department, University Center of Espírito Santo do Pinhal - UNIPINHAL. Espírito Santo do Pinhal, SP, Brasil. 
that a training program with the use of elastic resistance in young adults promoted adaptations in skeletal muscle, both in men and women.

In addition to showing good results with young adults, elastic resistance training is also effective for use in the elderly, with a systematic review by Martins et al. [9] found positive changes in musculoskeletal health, such as muscle hypertrophy, decreased body fat and increased muscle strength and physical performance, of elderly people undergoing elastic resistance training.

However, such results can only be observed when the training program respects the training variables, with the positions of the American College of Sports Medicine being a safe reference for training planning [10].

\section{Planning the Training}

When planning a training program, one of the fundamental points is the load to be used, being the determination of it when using traditional training carried out in different ways. In the case of elastic resistance training, an interesting methodology is the test of maximum number of repetitions.

To do this, initially define the bandage to be used (resistance grading is performed by colors), and then the maximum repetition is performed with that elastic band. Thus, the number of repetitions performed until the concentric failure will be the maximum load with that band, being the training load calculated according to this value. Example: if with the medium resistance bandage, 18 repetitions were performed for a given exercise, a training load of $60 \%$ to $80 \%$ of the maximum load will vary from 11 to 15 repetitions.

If after performing the test of number of repetitions it is found that with that band it is not possible to plan a workout with the minimum number of repetitions planned, it is interesting to consider the use of a lower resistance band, or else if it is offering a very strong resistance low, and the number of repetitions is too high, use a band of greater resistance.

The expectation is that the quarantine period will end soon, but if it lasts or for some other reason the use of elastic resistance training lasts, it is recommended that the load be resized every 4 weeks.

During training, some strategies can be used to increase the resistance, and consequently the load of the same band, such as folding it, however when doing this you should not fold it more than three times [11].
Kisner [12] also points out that exercise resistance is not only characterized by the strength of the elastic band, but is also influenced by the distance from the point of application of resistance to the main joint involved, as well as the direction of application of this resistance. Therefore, from the manipulation of these three variables (resistance, distance and direction), it is possible to create an exercise that presents decreasing resistance as the joint amplitude increases.

The choice of exercises to be performed is another important issue in planning, exercises that contribute to the improvement of functional capacity should be prioritized, since the level of physical activity is quite reduced in this period, it is essential to work large muscle groups, in addition to the program includes exercises for lower and upper limbs.

The number of sets should be between two and three, with the adjustment being made based on the number of repetitions and exercises, ensuring care regarding the training volume. The interval between sets, on the other hand, will vary according to the exercise and training objective, which can be 60 seconds, when singlejoint exercises are performed up to 180 seconds, in the case of multi-joint exercises that involve large muscles [10].

Thus, based on the variables already described, the training volume must be meticulously planned, remembering that in the case of elastic resistance training, the load is already linked to the number of repetitions.

\section{CONSIDERATIONS}

Due to its ease of use in different spaces, for the most varied audiences, security and, above all, the possibility of control, elastic resistance training has a high potential for application in domestic environments, and can considerably help the population that is quarantined and consequently without access to gyms and other spaces that allow training to be carried out using traditional methodologies, in addition to being safer than a series of exercise models, whose control of training variables is not possible or partially performed.

Thus, we recommend the use of elastic resistance training in order to minimize the detraining process of individuals who are in isolation, without the possibility of performing resistance training outside the domestic environment. 


\section{REFERENCES}

1. Gasparete LF, Boltd R, Borges DJ, Simão R, Fermino RC. Comportamento da força muscular após três semanas de destreinamento em adultos jovens. Rev Bras Ciênc Movo. 2010;18(1): 19-25. http://dx.doi.org/10.18511/rbcm. v18i1.1315

2. Miguel H, Campos MVA, Calixto RD. Musculação: Variáveis, princípios e métodos de treino para otimização da hipertrofia. São Paulo: Ixtlan; 2019.

3. Jensen J, Hölmich P, Bandholm T, Zebis MK, Andersen LL, Thorborg K. Eccentric strengthening effect of hip-adductor training with elastic bands in soccer players: a randomised controlled trial. Br J Sports Med. 2014;48(4):332-338. http://dx.doi.org/10.1136/bjsports-2012-091095

4. Wallace BJ, Winchester JB, McGuigan MR. Effects of elastic bands on force and power characteristics during the back squat exercise. J Strength Cond Res. 2006;20(2):268272. http://dx.doi.org/10.1519/R-16854.1

5. Colado JC, Garcia-Masso X, Pellicer M, Alakhdar $Y$, Benavent J, Cabeza-Ruiz R. A comparison of elastic tubing and isotonic resistance exercises. Int J Sports Med. 2010;31(11):810-817. http://dx.doi. org/10.1055/s-0030-1262808

6. Ghigiarelli JJ, Nagle EF, Gross FL, Robertson RJ, Irrgang JJ, Myslinski T. The effects of a 7-week heavy elastic band and weight chain program on upper-body strength and upper-body power in a sample of division 1-AA football players. J Strength Cond Res. 2009;23(3):756-764. http:// dx.doi.org/ 10.1519/JSC.0b013e3181a2b8a2.

7. Cotin S, Delingette $H$, Ayache N. A hybrid elastic model allowing real-time cutting, deformations and force-feedback for surgery training and simulation. The Visual Computer. 2000; 16(8): 437-452. http://dx.doi. org/0.1007/PL00007215

8. Hostler D, Schwirian C, Campos G, Toma K, Crill $M$, Hagerman $G$, et al. Skeletal muscle adaptations in elastic resistance-trained young men and women. Arbeitsphysiologie. 86:112-118. http://dx.doi. org/10.1007/s004210100495
9. Martins WR, de Oliveira RJ, Carvalho RS, de Oliveira Damasceno $V$, da Silva VZ, Silva MS. Elastic resistance training to increase muscle strength in elderly: a systematic review with meta-analysis. Arch Gerontol Geriatr. 2013;57(1):8-15. http://dx.doi.org/10.1016/j. archger.2013.03.002[

10. American College of Sports Medicine. American College of Sports Medicine position stand. Progression models in resistance training for healthy adults. Med Sci Sports Exerc. 2009;41(3):687-708. http://dx.doi. org/10.1249/MSS.0b013e3181915670

11. Hughes CJ, Hurd K, Jones A, Sprigle S. Resistance properties of Thera-Band tubing during shoulder abduction exercise. J Orthop Sports Phys Ther. 1999;29(7):413-420. http://dx.doi.org/10.2519/jospt.1999.29.7.413

12. Kisner C, Colby LA. Exercícios terapêuticos: fundamentos e técnicas. 3. ed. São Paulo: Manole; 1998. 